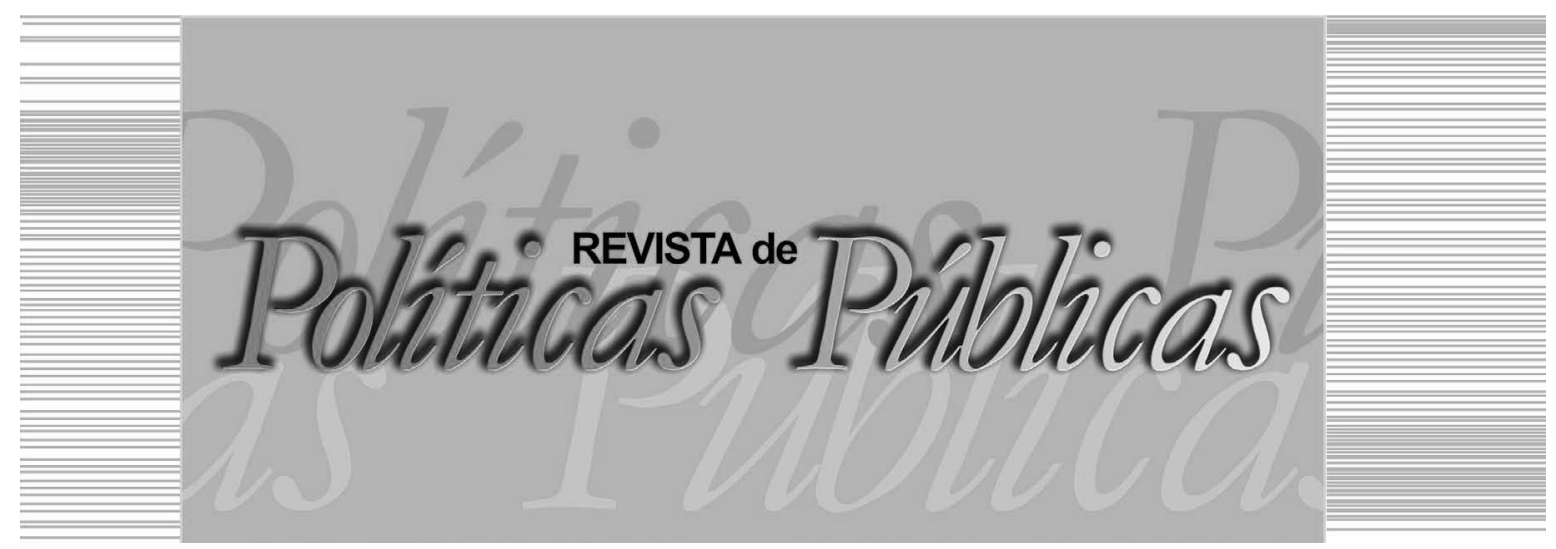

\title{
EGRESSOS DO SISTEMA PRISIONAL NO MERCADO FORMAL DE TRABALHO: oportunidade real de inclusão social?
}

\author{
Rafaelle Lopes Souzal \\ Andrea Maria Silveira ${ }^{2}$
}

\section{Resumo}

O presente estudo apresenta resultados do projeto de pesquisa intitulado: Inserção de Egressos do Sistema Prisional no Mercado Formal de Trabalho: oportunidades reais de inclusão social ou manutenção de uma classe excluída? Tem, ainda, o intuito de avaliar os resultados do Projeto Regresso, executado pelo Programa de Inclusão Social de Egressos do Sistema Prisional (PrEsp) e Minas Pela Paz (MPP), o qual visa à integração do egresso do sistema prisional no mercado formal de trabalho, por meio de parcerias estabelecidas pelo governo estadual e a iniciativa privada. Para isso, este estudo faz uma abordagem exploratória, com análise documental sobre o Projeto, realização de entrevistas semiestruturadas com representantes das empresas parceiras, do PrEsp, MPP e egressos contratados.

Palavras-chave: Egresso do sistema prisional, inclusão social, mercado formal de trabalho, Projeto Regresso.

\footnotetext{
1 Assistente Social, Doutoranda em Sociologia pela Universidade Federal de Minas Gerais (UFMG), pesquisadora do Centro de Estudos da Criminalidade e Segurança Pública - CRISP\UFMG. E-mail: rafaelle.lopes@yahoo.com.br/ Centro de Estudos de Criminalidade e Segurança Pública - CRISP/UFMG: Avenida Presidente Antônio Carlos de 4201 a 6499 - lado ímpar, Campus UFMG - Belo Horizonte, MG. CEP: 31270-010.

2 Graduada em Medicina, Doutora em Ciências Humanas pela UFMG, Professora associada do Departamento de Medicina Preventiva e Social e do Mestrado Profissional de Promoção da Saúde e Prevenção da Violência e do Programa de Pós Graduação em Sociologia. / Universidade Federal de Minas Gerais - UFMG - Faculdade de Medicina: Av: AlfredoBalena 190, Santa Efigênia - Belo Horizonte, MG. 30130-100.
} 


\title{
FORMER INMATES FROM THE PRISON SYSTEM IN \\ THE FORMAL LABOR MARKET: real opportunity of social
} inclusion?

\begin{abstract}
This paper presents some results of the research project entitled: former inmates from the prison system in the formal labor market: real opportunity of social inclusion? Which aimed to assess the results of Projeto Regresso, by Programa de Inclusão Social de Egressos do Sistema Prisional (PrEsp) and Minas Pela Paz (MPP). The project aims to integrate the prison system egresses in the formal labor market, through partnerships established by the state government and the private sector. This is an exploratory approach, with documentary analysis of the project, conducting interviews with representatives of partner companies, the PrEsp, MPP and hired former inmates.
\end{abstract}

Keywords: Former inmates. Social Inclusion. Formal Labor Market. Return Project.

\section{INTRODUÇÃO}

O presente trabalho apresenta os resultados do projeto de pesquisa intitulado: Inserção de Egressos do Sistema Prisional no Mercado Formal de Trabalho: Um olhar sobre o Projeto Regresso em Minas Gerais ${ }^{1}$, que teve o intuito de avaliar os resultados do Projeto Regresso, executado até o ano de 2015, pelo Programa de Inclusão Social de Egressos do Sistema Prisional (PrEsp) da Secretaria Estadual de Defesa Social do Estado de Minas Gerais (SEDS) em parceria com a Organização da Sociedade Civil de Interesse Público (Oscip) Minas Pela Paz (MPP). A pesquisa teve por objetivos: avaliar os resultados do Programa Regresso em Belo Horizonte e sua região metropolitana no período de 2010 a 2012; identificar os fatores facilitadores e dificultadores da implementação do projeto e identificar os critérios adotados pelas empresas parceiras para contratação do egresso.

O trabalho se configura como um importante fator de reinserção social para as pessoas que passaram pelo sistema prisional. Ainda durante o período do aprisionamento o trabalho aparece como aspecto essencial para quem cumpre a pena restritiva de liberdade, de acordo com o art. $28^{\circ}$ da Lei de Execução Penal (LEP): "O trabalho do condenado, como dever social e condição de dignidade humana, terá finalidade educativa e produtiva".

Além disso, só os ditos de bom comportamento são escolhidos para trabalhar; em alguns casos o trabalho pode ser remune- 
rado $^{2}$, servir para a remição de pena ${ }^{3}$ ou para concessão de alguns benefícios.

A obrigatoriedade do trabalho ao condenado está vinculada diretamente à pena e à progressão do regime. $\mathrm{O}$ art. $113^{\circ}$ da LEP estabelece que: "O ingresso do condenado em regime aberto supõe a aceitação de seu programa e das condições impostas ao Juiz." (BRASIL, 1984). Sendo que, logo em seguida, o art. $114^{\circ}$ da referida lei estabelece que: "Somente poderá ingressar no regime aberto o condenado que: I - estiver trabalhando ou comprovar possibilidade de fazê-lo mediamente." (BRASIL, 1984).

O Brasil, país com a maior população prisional da América Latina e a quarta no ranking mundial, apresentava ao final de 2014, segundo dados do Levantamento Nacional de Informações Penitenciárias (INFOPEN) do Ministério da Justiça (MJ), um contingente de 622.202 presos - estando na ocasião, $41 \%$ de presos provisórios aguardando julgamento. De acordo com a mesma fonte, Minas Gerais possui a segunda maior população prisional do país, com 61.392 custodiados. (BRASIL, 2014). Segundo a atual Secretaria de Administração Prisional de Minas Gerais (SEAP) aproximadamente, 14 mil custodiados trabalham enquanto cumprem pena nas unidades prisionais do Estado, com direito a remição de pena e remuneração de acordo com a LEP.

Diante desse contexto, é importante estudar o papel do trabalho na inclusão social de egressos do sistema prisional, enfocando a experiência do Projeto Regresso que fazia parte do PrEsp, no estado de Minas Gerais. O Projeto Regresso constituía uma iniciativa do Governo do Estado de Minas Gerais, em parceria entre a SEDS e MPP que previa por meio da Lei 18.401 , de 28 de setembro de $2009^{4}$, subvenção a empresas que contratassem egressos do sistema prisional, visando incentivar a contratação desse público. Sendo assim, alguns questionamentos merecem atenção: Qual o papel do trabalho para os egressos do sistema prisional atendidos pelo Projeto? O que a experiência do Projeto Regresso nos aponta para os limites e possibilidades do trabalho como forma de (re) integração social?

\section{A INSERÇ̃̃O DE EGRESSOS DO SISTEMA PRISIONAL NO MERCADO FORMAL DE TRABALHO}

No contexto internacional, alguns estudos abordam as dificuldades enfrentadas pelos egressos do sistema prisional, enfatizando 
a rede de apoio institucional como preponderante para o sucesso na obtenção de emprego (SHIVY et al., 2007), assim como a influência significativa do trabalho na redução das taxas de reincidência (PETERSILIA, 2005). A literatura nacional acerca do tema também é escassa, e mesmo os poucos estudos existentes retratam a inclusão de egressos no sistema prisional no mercado de trabalho sob a perspectiva destes, enfocando principalmente o trabalho como fator de inclusão social dentro (JULIÃO, 2010) e fora das prisões (PASTORE, 2011) e (re) construção da identidade de trabalhador. (SANTOS; MACIEL; MATOS, 2013).

Se o trabalho ainda se configura como importante, central na sociedade contemporânea, pensar o trabalho como fator de inclusão social se torna algo complexo, ainda mais em se tratando de egressos do sistema prisional. Para estes, a obtenção de um emprego, além de afiançar o capital econômico imediato para satisfação das necessidades sociais, como alimentação, moradia, vestuário, locomoção etc., eleva a autoestima e promove a dignidade destes sujeitos como forma de reconhecimento de que ele não está mais envolvido com o crime, já que ele obtém seu sustento e da maneira aprovada pela sociedade.

A carteira de trabalho assinada, sinônimo de emprego formal, configura-se como um importante instrumento de controle das populações excluídas - dos direitos fundamentais - especialmente o pobre e o negro: "sou trabalhador, não sou bandido" aparece no discurso corrente, como uma dicotomia que caracteriza o sujeito. O discurso moralista do "ou é uma coisa ou outra" (trabalhador ou bandido) é assimilado e reproduzido, já que naturalizado, tanto pela própria população marginalizada - que está à margem de direitos, sobretudo do direito do trabalho e por isso mesmo marginalizada no sentido criminal - quanto pelos aparelhos repressivos que colocam sob suspeição aquele que não tem como provar que é um trabalhador, ou um cidadão. (BARROS, 2005, p. 57, grifo da autora).

Para Santos, Maciel e Matos (2013), em seu estudo sobre os catadores de lixo egressos do sistema prisional em Fortaleza, foi possível constatar precariedade do trabalho anterior ao trabalho da catação, atrelados a condições de pobreza, pouca escolaridade e experiência, e quase nenhuma qualificação profissional; conferindo instabilidade e ocupações consideradas desqualificadas. 
Uma pesquisa relizada por Ruiz (2010), com o intuito de analisar os aspectos sociais relacionados com a reinserção social de egressos do sistema prisional, na Colômbia, constatou que atitudes favoráveis à inserção de egressos no mercado de trabalho ocorriam somente se os candidatos aos postos de trabalho tivessem sido condenados por delitos considerados mais leves. Ser mulher e não ser reincidente também era fator positivo para uma suposta contratação. Além disso, um discurso mais positivo por parte dos entrevistados era observado naqueles que possuíam um maior conhecimento sobre a temática prisional, ou proximidade com alguém que já passou pela prisão.

Segundo Petersilia (2003), nos EUA a empregabilidade aparece como o mais importante veículo para potencializar a (re) integração e afastamento do crime. A pesquisadora evidencia que uma parcela considerável das pessoas que passam pela prisão nos EUA possui pouca experiência profissional e é prejudicada pelas barreiras legais que impedem egressos de realizarem uma série de atividades: baixo nível educacional e pouca experiência profissional; uso de drogas e questões de saúde mental, residência em periferias que são distantes dos grandes centros da cidade, onde se localizam maiores ofertas de emprego; falta de motivação e atitudes de desconfiança e alienação em relação ao trabalho tradicional.

\begin{abstract}
No caso dos egressos, a saída da prisão e a busca de programas de apoio é pautada pela crença na reinserção pelo trabalho. No imaginário desses sujeitos, em muito reforçado pelos discursos judiciais e prisionais, há saída para aqueles que "foram bons e tiverem se arrependido", passando a viver de acordo com as regras sociais, como trabalhadores. O tipo de trabalho almejado pelos egressos é trabalho formal, o assalariado, que insere os trabalhadores no mercado, com todas as suas concessões e garantias. (MADEIRA, 2008, p. 325, grifo da autora).
\end{abstract}

De acordo com Pastore (2011), a inserção de egressos no mercado de trabalho é algo complexo e que requer a compreensão de uma série de fatores individuais, sociais e econômicos. Ademais, em muitos casos, os egressos são pouco preparados para encarar uma dinâmica de trabalho formal que exige o cumprimento de certas normas e mudança de alguns hábitos. Desse modo, Pastore (2011) defende que, programas que atuem na inserção laboral de egressos do sistema prisional devem objetivar o não retorno dos egressos a situações de risco que podem levar ao crime. Por isso, é necessá- 
rio atuar numa lógica que não objetive a simples contratação, mas também os efeitos positivos do trabalho sobre outras dimensões da vida do egresso do sistema prisional, como relações comunitárias e familiares.

Contudo, para Pastore (2011, p. 33), empregar não é a solução imediata contra crime e reincidência:

Estudos no campo do desemprego mostram que na prevenção da reincidência, a qualidade do emprego é mais importante que a oportunidade. $\mathrm{O}$ ambiente de trabalho, a segurança e os salários oferecidos pesam mais que o emprego em si. Afinal trabalhar é mais do que realizar uma tarefa. O trabalho é cercado de normas sociais, valores expectativas e relacionamentos que trarão satisfação e guiarão o comportamento das pessoas. Tais fatores é que influenciarão a permanência no emprego.

Do ponto de vista dos empregadores, uma pesquisa realizada pelo Crime and Justice Institute com empregadores de Boston (EUA) verificou a grande relutância dos empresários em contratar egressos do sistema prisional, em comparação com qualquer outro segmento considerado desfavorecido socialmente. A disposição para contratá-los, segundo a pesquisa, é influenciada pelo tipo de indústria, a gravidade do crime cometido pelo candidato a emprego, e experiência de trabalho desde a saída da prisão. Complementa de forma negativa o quadro, o fácil acesso aos antecedentes criminais em alguns estados norte-americanos e, inúmeras barreiras legais impostas a quem já cumpriu pena privativa de liberdade.

Nesse sentido, a contratação de egressos do sistema prisional, segundo a pesquisa, depende de fatores individuais, considerando principalmente as habilidades não técnicas destes sujeitos como: boa comunicação, concentração, compromisso com o trabalho e vontade de aprender. Além disso, o fato de o egresso ter participado de algum programa de inserção laboral durante o período de aprisionamento ou próximo a sua liberação, também é um ponto positivo a ser considerado por aqueles que pretendem contratar egressos do sistema prisional. Sendo assim, os incentivos fiscais que podem ser concedidos às empresas não se configuraram como fator mais atrativo para contratação de ex- detentos.

Diante do exposto, análises que contemplem percepções tanto positivas quanto negativas dos empregadores podem contribuir de forma mais efetiva para melhor formulação, implementação e mo- 
nitoramento de projetos que atuem com contratação de pessoas que passaram pela privação de liberdade.

\section{PROJETO REGRESSO}

Por meio da Lei Estadual no 18.401/2009, ampliado em 2013 pela Lei $\mathrm{n}^{\circ} 20.624$, de 16 de janeiro de 2013, o Projeto Regresso foi criado em parceria entre o PrEsp e MPP, e estabelecia a concessão de subvenção econômica a empresas que contratassem formalmente egressos do sistema prisional atendidos pelo PrEsp. (MINAS GERAIS, 2009). Em consultas a documentos elaborados pelo MPP, o Projeto Regresso surgiu a partir de estudos realizados pela própria Oscip sobre o Sistema Prisional de Minas Gerais, que apontou a necessidade de criação de uma iniciativa que apoiasse a inserção laboral de egressos do sistema prisional. $\mathrm{O}$ grande incentivo para o sucesso de Execução do Projeto, segundo o MPP, seria o pagamento a uma subvenção econômica no valor de dois salários mínimos por cada egresso contratado por empresas parceiras do Projeto. (INSTITUTO MINAS ELA PAZ, 2012).

Desde sua implementação, o Projeto Regresso foi uma importante frente de atuação do PrEsp. Executado em parceria com o MPP, a grande vantagem voltada ao público egresso do sistema prisional era a não exigência do atestado de antecedentes criminais, por parte das empresas parceiras do Projeto.

As empresas que manifestavam interesse em participar do projeto deveriam se credenciar, segundo critérios estabelecidos pela Edital de Credenciamento ${ }^{5}$. Após conferência positiva do setor jurídico da SEDS, as empresas poderiam formalizar a abertura de vagas junto ao MPP.

A efetiva atuação do Projeto iniciou-se em 2010, no qual 223 egressos foram encaminhados, e deste contingente, 73 foram contratados. No ano posterior, 350 encaminhamentos para as empresas conveniadas ao projeto foram realizados, e, deste total, 76 egressos foram contratados.

Aproximadamente 50 empresas disponibilizaram vagas, desde a implementação do Projeto, em variados segmentos como: mineração, indústrias de serviços alimentícios, comércio varejista, panificação, indústria têxtil, indústria automobilística, transportes, indústria de borracha, lavanderia, telemarketing, destacando maior 
parte das vagas para o setor de construção civil e limpeza urbana. Do total de empresas conveniadas, segundo o MPP, somente seis empresas solicitaram subvenção econômica para contratação de egressos.

Cada parceiro, além das empresas conveniadas, possuía atribuições específicas no que tange à Execução do Projeto: cabia ao MPP a prospecção de empresas e vagas destinadas ao público atendido; monitoramento de todo o processo seletivo das empresas; acompanhamento do trabalho executado pelo egresso junto à empresa e elaboração de relatórios sobre a execução do Projeto. As atividades atribuídas ao PrEsp não diferiam muito das ações já realizadas pelo Programa em seu cotidiano: acolhimento, encaminhamento ao mercado de trabalho e acompanhamento. Segundo gestores do Programa, o acompanhamento dos egressos era essencial para assegurar a efetividade na inclusão social.

Originalmente, as empresas que optavam por fazer convênio com o projeto poderiam receber dois salários mínimos mensais por egresso contratado, independente do cargo/função, por um período máximo de 24 meses. Para participar, cada empresa deveria consultar o edital de credenciamento e cumprir as formalidades descritas no documento de adesão

De acordo com as diretrizes do Projeto, as empresas poderiam abrir processos seletivos especíicos para os egressos, ou seleções abertas para pessoas que estão se candidatando a vagas de trabalho sem qualquer interferência da iniciativa. Na divulgação do processo seletivo, as empresas poderiam fazer exigências em relação à vaga ofertada: experiência, qualificação, idade, porte físico do candidato e distância do local de moradia. Em nenhuma hipótese os técnicos sociais que encaminhavam os egressos aptos à vaga pretendida divulgavam o tipo de delito que levou à condenação. Para formalização do encaminhamento, um formulário era preenchido com informações pessoais do candidato e do processo seletivo a ser entregue no dia da entrevista.

\section{SÍNTESE DOS RESULTADOS}

Nos anos estudados foram encaminhados 1.112 egressos para o Projeto. Em 2012 foram encaminhados 644 egressos, dos quais 201 pessoas foram contratadas. No ano seguinte, 469 egressos foram encaminhados e 147 contratados. Entre aqueles contratados pelas empresas, 58\% concluíram o ensino fundamental. Quanto à situação 
jurídica dos contratados, $42 \%$ estavam em liberdade condicional, $40 \%$ em prisão domiciliar e $16 \%$ em liberação definitiva.

O tempo médio entre contratação e saída do emprego foi de 149 dias em 2012, e 117 dias no ano seguinte. O maior tempo de permanência no trabalho foi verificado entre os egressos entre 30 e 39 anos. Os principais motivos de saída do trabalho foram: demissão pela empresa (73\%), pedido de demissão (9\%) e abandono (17\%).

A análise qualitativa apontou como maiores dificuldades dos egressos: o ajustamento às regras do mundo do trabalho (cumprimento de rotinas, horários, obediência à hierarquia etc.), concentração de postos de trabalho em atividades braçais, frustrando expectativas de trabalho e renda almejada; e, por fim, dificuldades das empresas em fazer a gestão de uma força de trabalho com este perfil.

Ademais, houve a realização de quatro entrevistas com representantes das empresas, cinco entrevistas com egressos inseridos formalmente no mercado de trabalho via Projeto Regresso, além de três entrevistas realizadas com representantes do PrEsp e MPP.

\section{- Percepção dos Egressos}

Dos egressos entrevistados durante a realização desta pesquisa, dois ainda trabalhavam nos mesmos cargos para os quais foram encaminhados pelo PrEsp e aprovados em processo seletivo em 2013 e 2014 respectivamente. Os demais não exerciam atualmente atividade laboral formal: um trabalhava na venda de livros usados e os demais relataram realizar bicos esporádicos. Os dois egressos que ainda permaneciam trabalhando atuavam como auxiliar de lavanderia.

Sobre as experiências profissionais até a prisão, somente um entrevistado relatou ter sempre trabalhado; os demais mencionaram atividades pontuais de curta permanência, em cargos que não exigiam qualificação e grande nível de escolaridade, como servente de pedreiro, doméstica, auxiliar de carga e descarga, flanelinha etc.

Todos os entrevistados declararam ter exercido algum tipo de atividade laboral durante o aprisionamento para fins de remição, exceto um egresso que também foi remunerado pelo trabalho exercido. Segundo relato dos entrevistados, as atividades foram na área de rouparia, limpeza, produção de embalagens e artesanato. Todavia, é explicitado na fala dos entrevistados que o trabalho executado 
durante a experiência prisional não contribuiu para melhor inserção laboral após a liberação, funcionando mais como um passatempo.

Trabalhava pra poder ter uma ocupação, porque ali dentro você pensa muita besteira. Ter uma ocupação. Aí depois quando eu saí de lá eu voltei lá e peguei um troquinho, um dinheiro. (Informação verbal $)^{6}$.

Foi bom, né? Pelo menos eu distraia a minha mente um pouco, do lado de fora, distraia minha mente. Já pensou a gente num lugar assim sem fazer nada? A gente tendo uma atividade, fazendo as coisas, trabalhando, o tempo passa, a gente tem mais... né? (Informação verbal) ${ }^{7}$.

Ah, não. Tipo assim, trabalhar... Eu fazia mais artesanato assim, fraga? Para ver se acabava o dia. Eu ficava na "Ala 04" que era a ala de artesanato e de lá a gente fazia os artesanatos e conseguia levar para alguma feira, é... com três dias de trabalho diminuía um. (Informação verbal, grifo nosso) ${ }^{8}$.

Sobre a atividade exercida pelos egressos contratados pelas empresas parceiras do projeto, destacam-se pontos positivos como o fato de ter um emprego, bom relacionamento com chefias imediatas e demais colegas de trabalho, assim como alguns pontos negativos, como baixos salários e alguns aspectos exigidos pela função (trabalho ser pesado, repetitivo).

Na empresa lá eles me tratam super bem, nunca me perguntaram nada desse negócio de presidiário. Me aceitou do jeito que eu sou, mesmo sabendo do meu passado. (Informação verbal) ${ }^{9}$.

Ah, a experiência que eu tive foi de conhecer pessoas boas que estavam do lado lá trocando altas ideias bacanas e que agregou foram novos conhecimentos mesmo, fraga? Porque o salário assim, se for para julgar, até o dos pessoal assim, é um salário meio triste fraga? (Informação verbal) ${ }^{10}$.

ah.. o encarregado falava muito bem de mim, até hoje, entendeu? Eles tudo falava bem do meu serviço, falava que eu era muito esperta, que nunca teve uma pessoa esperta como eu. O encarregado mesmo já falou várias vezes comigo. Aí tinha uma menina que ia reclamar, "tá indo reclamar de você", me chamou no escritório, "mas nós não damos confiança não, porque nós vê que você trabalha demais". Mas tinha uma mulher que tem dois anos que ela tava lá, peixinho, sabe? Peixinho, essas pessoas que é peixinho aí a 
gente não vigia, sabe fazer a cabeça... (Informação verbal, grifos nossos) ${ }^{11}$.

Um único aspecto concernente à condição de ser egresso do sistema prisional que apareceu na fala dos egressos refere-se ao uso da tornozeleira eletrônica:

[...] E outra, depois que eu tava há nove meses na rua, já trabalhando, eles me colocaram tornozeleira. Meus processos tava em Lagoa Santa, inclusive aqui até me ajudou bastante, o PrEsp. Eu tava sem saber. Fiquei um ano e oito meses de tornozeleira ainda, trabalhando, dando problema, porque dá problema, com medo de ser preso de novo, vinha aqui, a dona M. (técnica do programa) que me atendia, ela fez de tudo! Aí ela pediu minha transferência, "vou transferir você pra cá que é bem mais fácil" e foi certo. (Informação verbal, grifo nosso) $)^{12}$.

Dos egressos que ainda continuam trabalhando, nenhum foi promovido. Contudo, os entrevistados relataram a vontade de ascender profissionalmente dentro da empresa, mas não apresentaram planos concretos junto à empresa e nem fora dela.

Eu pretendo mesmo é lá dentro mesmo. Assim, subir, pra ganhar um pouquinho mais. Entendeu? Lá dentro tem essas oportunidades, depende da gente. Tem uns pessoal lá muito bacana comigo. (Informação verbal, grifo nosso) ${ }^{13}$.

Eu tô esperando a critério de Deus. Tô esperando os dias, os dias passar. Porque eles lá abrem a porta pra mim, não teve preconceito nenhum, eu sou muito grato a eles. Então eu deixo a critério de Deus, quando eu fizer um curso e tiver outro serviço eu converso com eles, agradeço o que eles fizeram por mim e sigo a minha vida. (Informação verbal) ${ }^{14}$.

Quando perguntados sobre a importância do trabalho em suas vidas, os entrevistados referiram perceber o trabalho como algo importante, que traz dignidade, renda e afastamento do crime.

O trabalho é a melhor coisa que tem! A gente acorda cedo, disposto, trabalha, volta pra casa sossegado, sem dever nada pra ninguém. Eu arrependi de ter envolvido nisso, né? Perdido seis anos da minha vida, só no sistema prisional, fora eu já perdi mais uns anos bons. Arrependi sim. (Informação verbal) ${ }^{15}$.

O trabalho é dignidade, né? Você trabalha pra você conquistar, né? Cada dia você conquista uma coisa na vida, né. Eu digo assim, é uma dignidade sua, né? É o seu direito, você trabalha e compra suas coisas, você quer comprar você compra, você não quer comprar você não compra, então o trabalho é uma dignidade que 


\begin{abstract}
a pessoa tem, é um caráter que a pessoa tem. Agora, se você não trabalha você não é ninguém, você fica dependendo dos outros pra comprar uma coisinha, uma coisinha outra, é ruim demais. Pior coisa é dever o outro. Deixar depois falar "eu ajudei aquela pessoa". (Informação verbal, grifo nosso) ${ }^{16}$.
\end{abstract}

É importante destacar que se percebeu grande dificuldade por parte dos entrevistados em informar sobre suas experiências de trabalho no que diz respeito ao sentido do trabalho para suas vidas e quais aspectos agregadores destas experiências. Expectativas referentes ao futuro também não foi algo contundente na fala dos entrevistados, mesmo daqueles que estão trabalhando atualmente.

\title{
- Percepção das empresas
}

Foram realizadas duas entrevistas com empresas pertencentes ao segmento de construção civil e as outras duas do setor de limpeza urbana, localizadas em Belo Horizonte e Região Metropolitana. Todos os representantes das empresas trabalhavam na área de recursos humanos.

A motivação para participar do Projeto se deu em maior grau pela necessidade de obtenção de mão de obra, segundo os entrevistados. Na fala de dois representantes da empresa, outra motivação foi o desejo de colaborar com a inclusão social de um segmento considerado excluído da sociedade: egressos do sistema prisional.

\begin{abstract}
A demanda para a contratação de egresso do sistema prisional, pela história, eu não estava aqui quando foi realizada a parceria, surgiu da indicação, da iniciativa de uma acionista. A gente começou essa parceria em 2009, por indicação dele, como mais uma opção, além de atender à uma demanda social, que a empresa $\mathrm{M}$. também tem essa preocupação, também como mais uma opção de captação de profissionais. (Informação verbal) ${ }^{17}$.
\end{abstract}

A subvenção oferecida pelo Governo, como forma de incentivar a contratação de ex- detentos, foi pouco solicitada pelas empresas. Dados do Instituto MPP comprovaram que apenas 27\% das organizações que contrataram esse tipo de mão de obra, desde a implantação do Projeto, entraram com o pedido de recebimento do benefício. Entre os entrevistados, houve relatos de que o processo é muito burocrático, o que acaba se tornando moroso e, muitas vezes, inviável para a empresa. 
De dificuldade, agora com relação à parceria com o Projeto Regresso, foi a questão da burocracia, que é uma burocracia pouco inteligente, por exemplo, nas nossas prestações de conta, chegou um ponto que a SEDS pediu para a gente preencher um formulário, nenhum problema com preencher formulário, mas que nem eles sabiam como que preenchia. Nós tivemos duas reuniões com a equipe do financeiro deles, da auditoria, pra eles tentarem explicar o que eles queriam daqueles formulários e eles não sabiam. É um exemplo [...] (Informação verbal) ${ }^{18}$.

Isso corrobora os relatos dos representantes das empresas sobre a motivação de adotar o Projeto Regresso, que está vinculada não apenas ao objetivo de obter vantagens econômicas, mas também como mais uma alternativa de captação de mão de obra, além do desejo de colaborar com a inclusão social de pessoas que já passaram pela privação de liberdade.

A disseminação sobre o projeto entre os demais funcionários e a aceitação do público interno se apresentou de forma distinta entre as empresas. Todas as empresas mantiveram sigilo quanto à condição jurídica dos egressos contratados, sendo esta informação restringida ao departamento de RH. Em apenas uma empresa os encarregados são informados. Para todas as empresas pesquisadas não houve impedimentos caso o próprio egresso relatasse sua história aos colegas de trabalho.

\begin{abstract}
A gente comunica que é egresso somente para quem vai entrevistar, que são os encarregados, mestres, mas há uma confidencialidade, eles não saem espalhando na obra ou para ninguém da empresa que aquela pessoa, que aqueles candidatos são egressos. Mas é muito tranquilo, os próprios egressos compartilham da sua experiência. Teve inclusive um caso de um específico que participou de palestras em todas as obras, é muito aberto para isso, para falar da mudança de vida, porque a gente encontra na obra pessoas com perfis muito semelhantes ao de egresso, com uma história de vulnerabilidade, não passaram pelo sistema penitenciário, mas tem características em comum. Então ele participou como demonstração mesmo de mudança. (Informação verbal) ${ }^{19}$.
\end{abstract}

Entretanto, percebem-se efeitos diferentes quando o egresso relata sua experiência prisional:

E na realidade, o treinamento que a gente proporcionou para os encarregados administrativos de obra, é que a obra não precisava saber, além dele, que ele era do projeto. Porque não tinha necessidade. Eu acho que se pudesse acontecer qualquer coisa na obra, eles já poderiam ficar ligados "ah, pode ser o pessoal do projeto", 
então era uma coisa que ficava mais sigilosa. Então, se não partisse do próprio funcionário, na hora do DDS de manhã, querer falar alguma coisa, se expor, ninguém mais dentro da obra, os encarregados, sabia [...]. Então assim, tinha alguns que faziam questão de falar: "olha, eu sou do projeto, eu sou ex presidiário" e se expunham, e a gente também não achava isso muito interessante. Tinha outros que não, trabalhavam normalmente, sem nenhum tipo de problema, nem disciplinar, nada, muito tranquilo. (Informação verbal, grifo nosso $)^{20}$.

Depende da forma com que eles passam. A gente não passa, não gosta de falar, pra não ter nenhum tipo de discriminação. Agora depende da forma que eles passam pra frente, porque às vezes passam de uma forma natural, agora outras pessoas passam querendo meio que amedrontar. Aí depende da forma que eles falam que a pessoa receber, né? Normalmente você trabalhar com uma pessoa ali, dependendo do crime que ela cometeu, querendo ou não isso deixa as pessoas meio que inseguras. Aí depende deles, fica a critério deles, se eles querem falar ou não. (Informação verbal) ${ }^{21}$.

Durante a execução do Projeto nas empresas pesquisadas, os entrevistados disseram enfrentar algumas dificuldades. A primeira delas, ainda na fase de contratação, referia-se à baixa qualificação e pouca experiência dos candidatos, o que dificultava a inserção em vagas consideradas mais qualificadas. Contudo, este fato era encarado como algo característico de um segmento vulnerável socialmente não específico de quem passou pelo sistema prisional. Em relação ao cotidiano de trabalho, as constantes faltas e baixa produtividade dificultaram boa execução do trabalho segundo os entrevistados, inclusive sendo os principais motivos de demissões, mas que também não era algo peculiar de ser egresso do sistema prisional.

Todavia, os efeitos objetivos (restrição de horários, uso de tornozeleira, comparecimento a audiências) e simbólicos (estigma e preconceito) do restante cumprimento da pena privativa de liberdade apareceram como um fator dificultador em todas as empresas:

Olha, as vezes o que acontecia, a título de produtividade, porque na engenharia é produção e produção, tinha alguns que não poderiam ficar depois do horário porque tinham horário para entrar no albergue, as vezes eles ficavam se sentindo prejudicados, porque tinham a oportunidade de ganhar hora extra e não podiam ganhar, porque tinham horário para entrar. Mas no decorrer virou uma habitualidade, uma rotina, então eles já comunicavam quando era a próxima visita, quando ele tinha que comparecer, então não trazia tanto transtorno assim. O que eu conseguia perceber é que as vezes 
eles ficavam chateados com o horário que eles tinham que entrar no albergue, então as vezes a gente ia ter um trabalho que eles teriam a possibilidade de fazer hora extra e não poderiam, eles não tinham flexibilidade de horário. (Informação verbal) ${ }^{22}$.

Pontos negativos "é" a bendita da tornozeleira. É um ponto negativo, porque o trem quando começa a apitar, só Jesus. Esse P. H. mesmo eu tive bastante problema com ele no início. [...] Ele foi até preso, né? Ele até voltou e saiu de novo. Assim, questão do horário, igual sábado, tem alguns que não podem trabalhar porque não é liberado. (Informação verbal, grifo nosso) ${ }^{23}$.

Apesar das dificuldades, os entrevistados referiram haver muitos pontos positivos, como o comprometimento e a força de vontade do egresso na busca por melhores possibilidades de inclusão social, que ocasionaram promoções e elogios de chefias imediatas, além do reconhecimento de outros funcionários da empresa da contribuição social da parceria. È importante ressaltar que na fala dos entrevistados a questão do compromisso com inclusão social deste público é bastante enfatizada.

No que se refere à parceria com o PrEsp, sobre o acompanhamento dos contratados via projeto, não houve consenso entre os entrevistados sobre a efetividade dessa parceria. Alguns entrevistados consideraram o acompanhamento essencial e agregador, ao passo que outros declararam não haver um acompanhamento de qualidade:

Eu até deixava isso muito claro, que dependendo do volume de obras e tudo mais, se eu não tivesse esse acompanhamento do Programa para dar o suporte, eu acho que não teria condições de dar continuidade. A gente teve um funcionário, que eu estou me recordando, que tinha envolvimento com drogas, então tinha dia que ele não produzia, ele ficava num canto isolado. Então eu acho que se não existisse esse suporte pra a gente está tendo um problema com ele assim, será que tem jeito de vocês fazerem alguma intervenção? eu não teria como nem tentar alguma outra possibilidade de ajudá-lo. Então sem o acompanhamento do projeto, acho que eu não assumiria essa responsabilidade sozinha. Então tem que existir. (Informação verbal) ${ }^{24}$.

Bom, a gente acompanha da mesma forma que acompanha todos os outros, muito quando eles demandam, quando acontece alguma coisa. Mas não tem um acompanhamento diferenciado, porque a nossa ideia é tratar de forma igual. O acompanhamento do programa é muito bacana, são pessoas muito carentes de informação, e o programa oferece um acompanhamento que é de orientação jurídica, de acompanhamento psicológico, paralelo ao trabalho do $\mathrm{RH}$ 
da MASB, uma mão de obra que a gente talvez não desse conta de realizar, então vem só para agregar. (Informação verbal) ${ }^{25}$.

Falta. Falta mais acompanhamento. Eu falei assim.. Ou uma vez a cada quinze dias, ou uma vez a cada trinta dias. [...]. Essa informação [sobre as restrições da pena] que não é passada pra gente, quando pode, qual data que pode. No sentido assim, "feriado pode? Qual horário?”, “sábado e domingo pode? Qual horário?”eles acabam aproveitando, porque quando eles veem que não tem esse [acompanhamento].. .esse controle... (Informação verbal, grifos nossos) $)^{26}$

Exceto em um caso, as empresas consultadas afirmam não realizar projetos internos para a (re) socialização desse público, mas se mostraram abertas e dispostas a contribuir para o desenvolvimento de ações deste tipo.

\section{CONCLUSÃO}

Como parte integrante de uma Política Estadual de Prevenção à Criminalidade do Estado de Minas Gerais, o PrEsp, procura, em certa medida, dar conta das vulnerabilidades sociais e estigmas decorrentes do aprisionamento e, também, prevenir socialmente a violência e o crime por meio de ações de atendimento psicossocial e jurídico, encaminhamento para a rede de proteção social e inserção no mercado de trabalho.

Reconhece-se que a inserção no mercado de trabalho para egressos do sistema prisional encontra pouca oferta de oportunidades de trabalho. Quase como regra, esse público tem baixo nível de escolaridade e habilitação profissional e é perseguido pelo estigma. A experiência do Projeto Regresso demonstrou que tais características respondem pelos baixos salários dos empregos oferecidos (principalmente quando comparados às expectativas de renda de algumas atividades ilegais), o que, muitas vezes, constitui um desestimulo à adesão às poucas ofertas de emprego no mercado formal de trabalho.

A baixa qualificação, os altos índices de turnover, a dificuldade em criar vínculos com a empresa, e a adaptação às regras laborais também foram apontados. No que concerne às questões relacionadas ao cumprimento do restante da pena, causam efeitos danosos não só para obtenção de emprego, mas em outras instâncias na vida desses sujeitos (comunitária, familiar, psicológicas). 
Infelizmente, o Projeto Regresso teve suas atividades encerradas no final de 2015, após mudanças na gestão estadual. Contudo, o PrEsp continua atuando para inserir egressos no mercado de trabalho por meio de parcerias com a rede municipal ou com empresas que optem por ofertar vagas de emprego em negociação direta com o Programa.

O grande desafio para programas $\backslash$ projetos que lidam com segmentos estigmatizados, marginalizados é romper com rótulos, estigmas e pré-conceitos. Contudo, mesmo com a existência de tais iniciativas, a forma como este indivíduo é visto pelos demais não é atenuada e tampouco efeitos (re) socializadores são observados em grande escala. $\mathrm{O}$ que esses programas e projetos já existentes inovam de fato? Como formular e implementar programas sociais que desconstruam essas dimensões (rótulo e estigma de eterno criminoso)? É possível atenuar esses aspectos?

Essa lacuna apresentada necessita ser aprofundada em pesquisas posteriores, contudo os achados deste trabalho podem trazer contribuições importantes para a melhoria de Programas e Projetos que atuam na inclusão social de pessoas que passaram pela privação de liberdade. Além disso, é importante considerar que o indivíduo egresso do sistema prisional carrega consigo representações produzidas pela prática das instituições do sistema de justiça criminal e a moralidade pública, então, a esse sujeito se apresenta uma reação muito mais contundente: como argumentos em defesa da sua eliminação, incapacitação e maior controle por parte das instâncias do sistema de justiça criminal.

\section{REFERÊNCIAS}

BARROS, V. A. A função política do trabalho e a ordem social. Veredas do Direito, Belo Horizonte, v. 2, n. 4, p. 51-66, 2005.

BRASIL. Ministério da Justiça. Departamento Penitenciário Nacional. Levantamento Nacional de Informações Penitenciárias INFOPEN. Brasília, DF, dez. 2014. Disponível em:<https://www.conjur.com.br/ dl/infopen-dez14.pdf $>$. Acesso em: 20 set. 2015.

Presidência da República. Lei ${ }^{0} 7.210$, de 13 de julho de 1984. Institui a lei de execução penal. Diário Oficial da União, Brasília, DF, 13 jul. 1984. 
INSTITUTO MINAS PELA PAZ. Relatório de Atividades - 2011: inserção profissional de egressos e apenados do sistema prisional. Belo Horizonte, jan. 2012. Disponível em: <http://www.minaspelapaz. org.br/wp-content/uploads/2017/02/Relatorio-Regresso-2011-2012. pdf $>$. Acesso em: 11 de junho de 2015.

JULIÃO, E. F. O impacto da educação e do trabalho como programas de reinserção na política de execução penal do Rio de Janeiro. Revista Brasileira de Educação, Rio de Janeiro, v. 15, n. 45, p. 529-543, 2010.

MADEIRA, L. M. Trajetórias de homens infames: políticas públicas penais e programas de apoio a egressos do sistema penitenciário no Brasil. 2008. 359 f. Tese (Doutorado) - Curso de Sociologia, Universidade Federal do Rio Grande do Sul, Porto Alegre, 2008.

MINAS GERAIS. Lei n. 18401, de 28 de setembro de 2009. Autoriza o Poder Executivo a conceder subvenção econômica às pessoas jurídicas que contratarem egressos do sistema prisional do Estado. Diário do Executivo, Belo Horizonte, p. 1, 29 set. 2009.

PASTORE, J. Trabalho para Ex- Infratores. São Paulo: Saraiva, 2011.

PETERSILIA, J. Hard Time: Ex-Offenders Returning Home After Prison. Corrections Today, [S. 1.], v. 67, n. 2, p. 66-71, apr. 2005.

RUIZ, J. I. Actitudes sociales hacia ex reclusos: un estudio exploratório. Suma Psicológica, Bogotá, v. 17, n. 2, p. 169-177, dic. 2010.

SANTOS, J. B. F. dos; MACIEL, R. H. M. de O.; MATOS, T. G. R. Reconquista da identidade de trabalhador por ex-detentos catadores de lixo. Caderno CRH [Online], Salvador, v. 26, n. 68, p. 377-390, maio/ago. 2013. Disponível em: $<$ http://www.scielo.br/pdf/ccrh/ v26n68/a11v26n68.pdf>. Acesso em: 15 nov. 2015.

SHIVY, V. A. et al. Ex-Offenders Reentering the Workforce. Journal of Counseling Psychology, Washington, DC, v. 54, n. 4, p. 466-473, 2007.

\section{Notas}

1 O referido projeto foi financiado pelo Conselho Nacional de Desenvolvimento Científico e Tecnológico (CNPQ).

2 Art. $129^{\circ}$ da LEP.

3 Art $126^{\circ}$ da LEP que prevê a remição da pena pelo trabalho: a cada três dias trabalhados um dia de pena é diminuído.

4 Ampliada pela Lei $n^{\circ} 20.624 / 2013$ 


\title{
EGRESSOS DO SISTEMA PRISIONAL NO MERCADO FORMAL DE TRABALHO:
}

\author{
oportunidade real de inclusão social?
}

5 Disponível em:<http://minaspelapaz.org.br/useruploads/files/Edital_2013_ Programa_Regresso.pdf $>$.

6 Depoimento retirado da entrevista feita com E2.

7 Depoimento retirado da entrevista feita com E4.

Depoimento retirado da entrevista feita com E5.

9 Depoimento retirado da entrevista feita com E2.

${ }^{10}$ Depoimento retirado da entrevista feita com E5.

${ }^{11}$ Depoimento retirado da entrevista feita com E4.

${ }^{12}$ Depoimento retirado da entrevista feita com E1.

${ }^{13}$ Depoimento retirado da entrevista feita com E1.

${ }^{14}$ Depoimento retirado da entrevista feita com E2.

${ }^{15}$ Depoimento retirado da entrevista feita com E2.

${ }^{16}$ Depoimento retirado da entrevista feita com E3.

${ }^{17}$ Depoimento retirado da entrevista feita com H, representante da Empresa 2.

${ }^{18}$ Depoimento retirado da entrevista feita com L, representante da Empresa 1.

${ }^{19}$ Depoimento retirado da entrevista feita com $\mathrm{H}$, representante da Empresa 1.

${ }^{20}$ Depoimento retirado da entrevista feita com B, representante da Empresa 3.

${ }^{21}$ Depoimento retirado da entrevista feita com I, representante da empresa 4.

${ }^{22}$ Depoimento retirado da entrevista feita com B, representante da Empresa 3.

${ }^{23}$ Depoimento retirado da entrevista feita com I, representante da Empresa 4.

${ }^{24}$ Depoimento retirado da entrevista feita com B, representante da Empresa 3.

${ }^{25}$ Depoimento retirado da entrevista feita com $\mathrm{H}$, representante da Empresa 2.

${ }^{26}$ Depoimento retirado da entrevista feita com I, representante da Empresa 4. 
